\title{
The Inaccuracy of Compensation System of Spindle Thermal Growth in Machine Tool Application and Its Solution
}

\author{
Yi-Lin He \\ Department of Mechanical Engineering \\ Buffalo Machinery CO., LTD., \\ Taichung, Taiwan \\ r47@mail.buffalo.com.tw \\ Jenq-Shyong Chen \\ Department of Mechanical Engineering \\ National Chung-Hsing University \\ Taichung, Taiwan \\ MichaelChen@dragon.nchu.edu.tw
}

\author{
Hsun-Fu Chiang \\ Department of Mechanical Engineering \\ National Chung-Hsing University \\ Taichung, Taiwan \\ r43@mail.buffalo.com.tw \\ Paul Chang \\ Department of Electrical Engineering \\ National Chang-Hua University of Education \\ Taichung, Taiwan \\ paulchang@mail.buffalo.com.tw
}

\begin{abstract}
The development of machine tool is toward high-speed, high-precision and smarter with high-end compensation techniques. The sensor and the data acquiring system are required in compensation system. However, the aliasing phenomenon can be observed in the existing data acquiring system in machine tool application. In this paper, one solution is proposed to overcome signal aliasing. The phenomenon which appears in spindle thermal growth compensation system is carried, and the improved system. is validated.
\end{abstract}

Keywords- aliasing filter, machine tool, compensation

\section{INTRODUCTION}

To increase the productivity and reduce the production error, the developments of machine tool industry have been toward high-speed, high-accuracy, especially in the die and mold and aerospace area. The machine errors come from the volumetric error [1],[2] and thermal error [3]-[6] which has great impact on machine tool quality. The calibration and compensation techniques have been widely applied in machine tool to address these issues [7]-[9].

The sensor signal is utilized to compensate the machine errors. The data acquiring module is setup to capture sensor signals. In digital signal process, the sampling rate must meet the requirement of Nyquist frequency to avoid aliasing issue [10]. Majority of practical applications, the sampling rate is higher than the maximum of interesting sensor frequency. This is called oversampling. In this way, the entire original signal could be reconstructed well under the sampling rate.

In the machine tool application, the sampling period of signal acquiring module is around several $\mathrm{ms}$ to tens $\mathrm{ms}$, hence, the bandwidth is up to among $10 \mathrm{~Hz} \sim 100 \mathrm{~Hz}$ (this is relatively low sampling rate). This parameter is usually dependent on the type of commercial PLC and NC system. However, some sensors bandwidth, for example, capacitive displacement sensor and eddy-current displacement sensor, is up to several $\mathrm{kHz}$. The bandwidth frequency of these sensors is higher than the signal acquiring module. This paper aims to measure and study aliasing phenomenon in aforementioned machine tool system, and the possible effect of the compensation system is discussed as well. Finally, aliasing phenomenon of validation system and testing method is presented.

II. PHENOMENON DESCRIPTION OF ULTRA LOW FREQUENCY ON THE MEASUREMENT MACHINE TOOL ACQUIRING EQUIPMENT

\section{A. The block diagram of the compensation system}

The block diagram is shown in Figure 1. Accuracy is influenced by spindle thermal growth [7], one tooltip compensation is designed to compensate deviation. If the sensor detects the deviation, the compensation system will control the servo driving system and mechanical chain to maintain position of spindle tooltip

One displacement sensor is integrated into the spindle structure, is detecting the distance to the measurement target. The detailed geometric and location can be referred to [7]. The signal of displacement sensor is measured by the Analog Input Module (AIM), which is an ADC in the Heidenhain Numerical Controller (NC) system [11].

In this study, the Heidenhain 5-axies controller is applied. The Heidenhain TNCscope is a data recorder released from Heidenhain $\mathrm{GmbH}$ with Version no. 4.1.33 and NC Software is 34059x-08 SP01 English (en). The "TNCscope" software is utilized to record the data from NC system and analyze the signal via Fast Fourier Transform (FFT). The specification of analog input module is shown in Table 1. According to the specification, the period of sampling can be 
chosen by 9 to $30 \mathrm{~ms}$. Because all I/O signal must be scanned in one sampling period without missing safety signal during machine operation, the sampling period cannot be too short. The system $21 \mathrm{~ms}$-sampling-period is chosen in this study.

The signal $V_{\text {dis }}$ contains sensing the thermal growth and mechanical noise. The mechanical noise is from the error of part machining and leads to unsmoothed surface of measured target. As shown in Figure 2, the periodic signal is measured by oscilloscope, as the spindle is operated in 20,000 RPM, for example, rotating frequency of spindle shaft is $333.3 \mathrm{~Hz}$, this will happen when the spindle is rotating. The moving-average filter is designed to eliminate the mechanical noise. The structure of moving-average filter is based on every two hundred sampling data. The tool-tip system will obtain a new compensation value $\mathrm{V}_{\mathrm{NC} \text {,ma }}$ by every 4.2 seconds. Typically, in spindle thermal growth, the time constant is long, for example it is up to tens to hundreds seconds. Hence, the mentioned moving-average filter is reasonable.

TABle 1. Specification of AnAlog InPUt Module

\begin{tabular}{|c|c|}
\hline Voltage Range & $-10 \mathrm{~V} \sim+10 \mathrm{~V}$ \\
\hline Load impedance & $>40 \mathrm{k} \Omega$ \\
\hline Resolution & $0.3 \mathrm{mV}$ \\
\hline $\begin{array}{c}\text { Range of sampling } \\
\text { period(cycle time) }\end{array}$ & $9 \sim 30 \mathrm{~ms}$ \\
\hline The testing sampling period & $21 \mathrm{~ms}$ \\
\hline
\end{tabular}

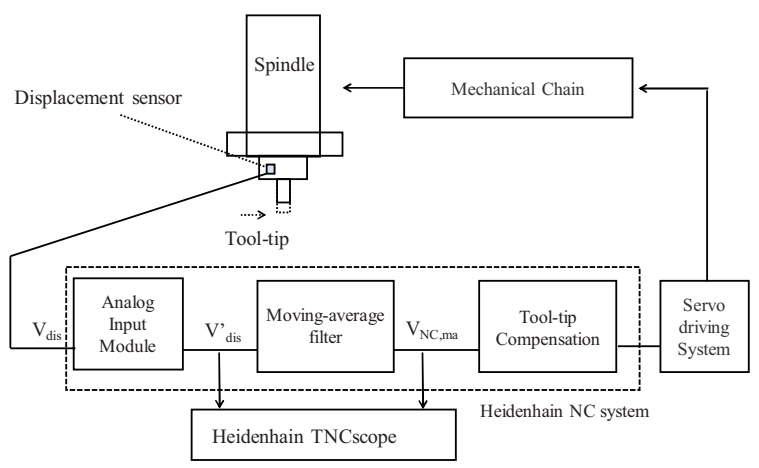

Figure 1. The compensation system

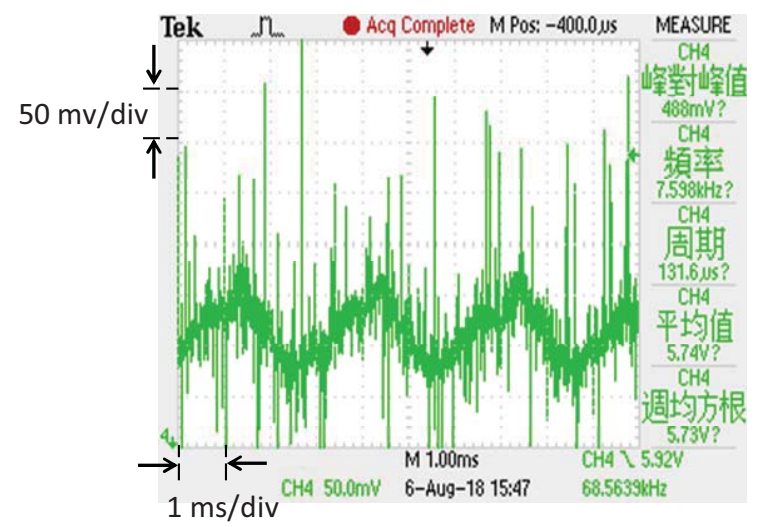

Figure 2. The displacement signal of the mechanical error

\section{B. Experimental design and result}

Several parameters are chosen to reveal phenomenon and tested spindle speed is listed in Table
2. Four center speeds are 5,000, 10,000, 15,000 and 20,000 RPM respectively. The step variation is one RPM. The testing time of every step is one minute. The maximum operation speed of the target spindle is 20,000 RPM, so the speed range of Range \#4 is 19,990 $\sim 20,000$ RPM.

TABLE 2. TESTING PARAMETER OF THE SPINDLE SPEED

\begin{tabular}{|c|c|c|c|c|}
\hline $\begin{array}{c}\text { Exp. } \\
\text { No }\end{array}$ & $\begin{array}{c}\text { Center } \\
\text { speed } \\
\text { [RPM] }\end{array}$ & $\begin{array}{c}\text { Variation } \\
\text { [RPM] }\end{array}$ & $\begin{array}{c}\text { Step } \\
\text { variation } \\
\text { [RPM/min] }\end{array}$ & $\begin{array}{c}\text { Speed } \\
\text { Range }\end{array}$ \\
\cline { 1 - 1 } $\begin{array}{c}\text { Rang } \\
\# 1\end{array}$ & 5,000 & & & $\begin{array}{c}4,990 \sim \\
5,010\end{array}$ \\
\cline { 1 - 1 } $\begin{array}{c}\text { Rang } \\
\# 2\end{array}$ & 10,000 & \pm 10 & & $\begin{array}{c}9,990 \sim \\
10,010\end{array}$ \\
\cline { 1 - 1 } $\begin{array}{c}\text { Rang } \\
\# 3\end{array}$ & 15,000 & \multirow{2}{*}{1} & $\begin{array}{c}14,990 \sim \\
15,010\end{array}$ \\
\cline { 1 - 1 } $\begin{array}{c}\text { Rang } \\
\# 4\end{array}$ & 20,000 & -10 & & $\begin{array}{c}19,990 \sim \\
20,000\end{array}$ \\
\hline
\end{tabular}

As shown in Figure 3, the measured results show clearly mechanical error and thermal growth. The thermal growth is changed slowly up to several minutes. The mechanical errors almost appear in whole testing period, as shown in Figure 3 (a) and (b). The LPF is worked in some operation zone, for example in Figure 3 Zone-P. However, when the spindle speed is close to the tested center speed, the LPF is invalid, as indicated in Zone-Q. Since the sampling frequency is much lower than the rotating frequency of spindle shaft, the aliasing phenomenon appears in the whole tested spindle speed range. In addition, all the Zone- $\mathrm{Q}$, the $\mathrm{V}_{\mathrm{NC} \text {,ma }}$ shown that the moving-average filter is invalid, the period of $\mathrm{V}_{\mathrm{NC} \text {,ma }}$ reach several minutes. This is defined as Ultra Low Frequency phenomenon.

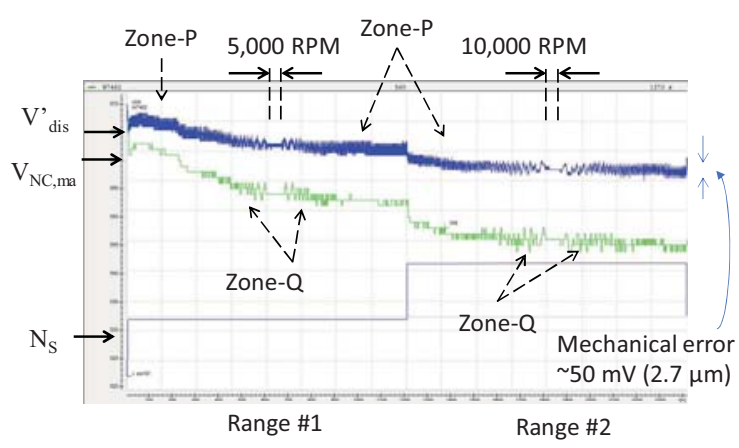

(a) the testing result of Range \#1 and Range \#2

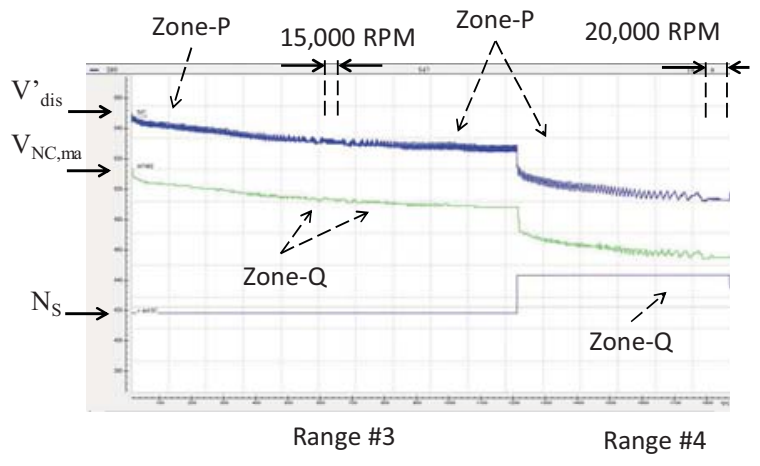

(b) the testing result of Range \#3 and Range \#4 Figure 3 . The testing result 


\section{The effect and disscussion}

In machine tool industry, the machine accuracy is scaled in several $\mu \mathrm{m}$. As shown in Figure 3 (a), for this case of tested spindle, the mechanical error is $2.7 \mu \mathrm{m}$. This cannot be ignored, since this error will show in the tool-tips of spindle, and cause compensation function to a failure. When this happen, there is periodic variation in the surface of the workpiece and leads to reduction of machining quality. The most final machining process is finishing, this process is to ensure the workpiece surface is smooth.

\section{IMPROVED SYSTEM DESIGN}

Due to the aliasing phenomenon, one simple solution is to insert an analog filter between displacement sensor and AIM, as shown in Figure 4. The filtered signal $\mathrm{V}_{\text {dis }}$ call $\mathrm{V}_{\text {dis,f. }}$. The $\mathrm{V}^{\prime}{ }_{\text {dis }}, \mathrm{V}_{\mathrm{NC}}$ and $\mathrm{V}_{\mathrm{NC} \text {,ma }}$ are represented digital signal, and saved in TNCscope. In this paper, a two-order passive LPF is chosen to filter the variation of the mechanical error, before the signal $\mathrm{V}_{\text {dis }}$ is sensed by AIM. The cut frequency of LPF is much lower than the frequency of 5,000 rpm center speed, to ensure the center frequency of spindle rotating shaft is filtered. The $40 \mathrm{~Hz}$ cut-off frequency is designed, The capacitance and resistance of LPF are $22 \mu \mathrm{F}$ and $180 \Omega$, respectively. The Bode diagram is shown in Figure 5.

The measurement result of improved system is shown in Figure 6. In the improved system, it shows that two phenomena, the aliasing phenomenon and Ultra Low Frequency phenomenon are no longer exist. For the aliasing phenomenon signal, compares the signal $V^{\prime}$ dis and $V_{\mathrm{NC}}$, all mechanical error are eliminated by the analog LPF. Due to the Ultra-Low Frequency phenomenon inherits from the signal aliasing, so this cannot be seen in the tested condition.

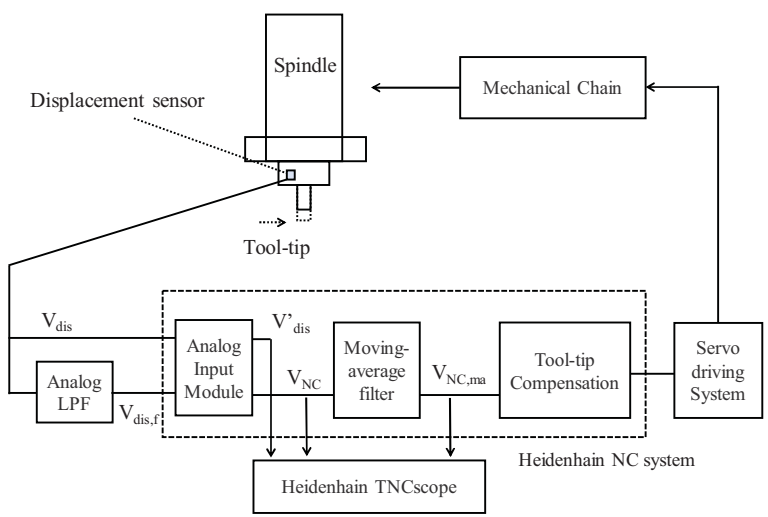

Figure 4. The diagram of improved system

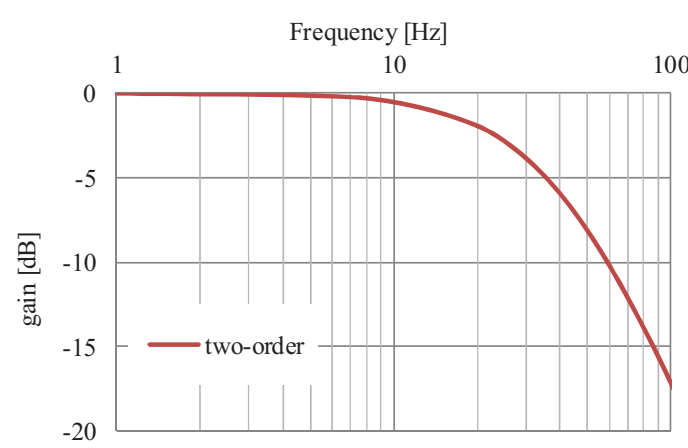

Figure 5. The Bode diagram of the designed LPF

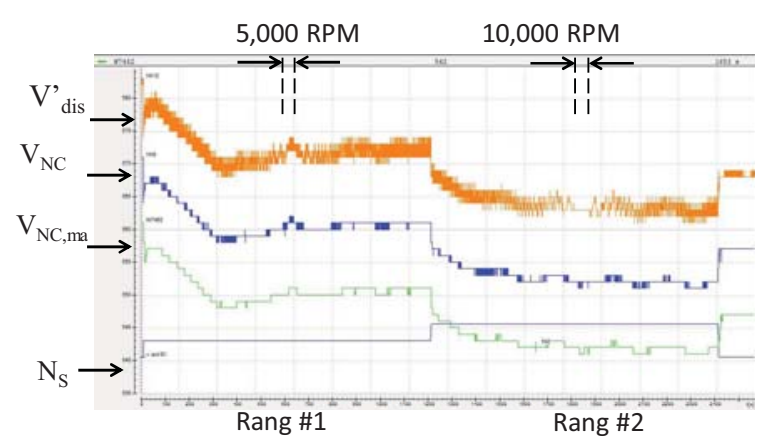

(a) the Range \#1 and Rang \#2

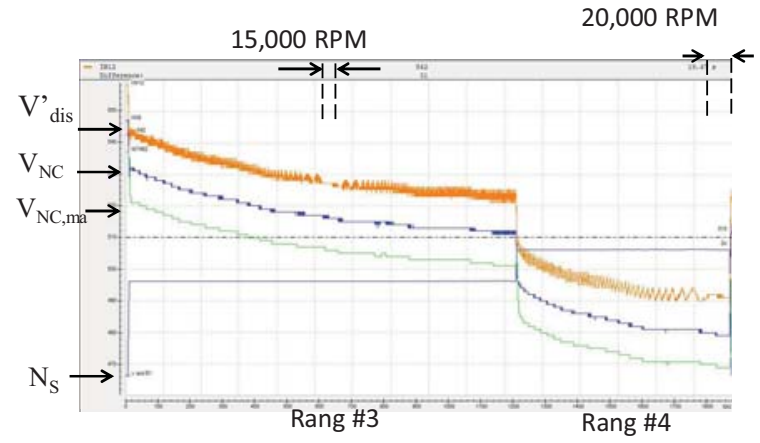

(b) the Range \#3 and Range \#4

Figure 6 . The improved testing result

One real cutting test is conducted in a $5 \mathrm{X}$ machine tool on a workpiece, the machine information can be found in reference [12]. To valid the improved system for machine tool application, several spindle speeds of obvious Ultra-Low frequency phenomenon are chosen, for example, 9,997 RPM and 9,999 RPM. Detailed test spindle speed is listed in Table 3 . There are 16 cutting test in total, as shown in Figure 7. In Figure 7, the surface quality for the improved system is better than that of un-improved system.

Table 3. Testing parameter of the spindle speed

\begin{tabular}{|c|c|}
\hline condition & Spindle Speed (RPM) \\
\hline NO.1 & 9,997 \\
\hline NO.2 & 9,999 \\
\hline NO.3 & 10,000 \\
\hline NO.4 & 10,001 \\
\hline NO.5 & 10,003 \\
\hline NO.6 & 19,997 \\
\hline NO.7 & 19,999 \\
\hline NO.8 & 20,000 \\
\hline
\end{tabular}

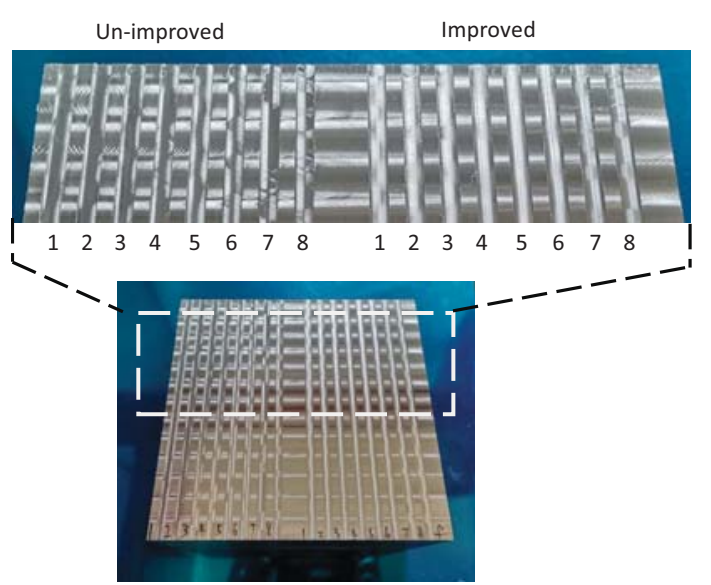

Figure 7. The photo of the real cutting test 


\section{DISCUSSION AND CONCLUSION}

In this paper, the aliasing phenomenon and UltraLow frequency phenomenon are observed in the existing data acquiring system of machine tool system. This makes inaccuracy in compensation system of spindle thermal growth. One cutting test is conducted to validate the proposed solution. The aliasing phenomenon is eliminated, Ultra-Low frequency phenomenon no longer appear which means that the spindle thermal growth compensation can be work in the whole operation range. The detailed design procedure of LPF will be studied in the near future.

\section{REFERENCES}

[1] An Wan, Libin Song, Jing Xu, Shaoli Liu, Ken Chen, "Calibration and compensation of machine tool volumetric error using a laser tracker," International Journal of Machine Tools and Manufacture, Vol.124, pp. 126-133, Jan. 2018.

[2] S. Xiang and Y. Altintas, "Modeling and compensation of volumetric errors for five-axis machine tools," International Journal of Machine Tools and Manufacture, Vol.101, pp. 6578, Feb. 2016.

[3] X. B. Ma et al., "Study on Spindle Thermal Field Distribution and Thermal Errors of Horizontal Machine Tool," Materials Science Forum, Vols. 697-698, pp. 273-276, 2012
[4] R. Ramesh, M. A. Mannan, A.N Poo, "Error compensation in machine tools - a review: Part II: thermal errors," International Journal of Machine Tools and Manufacture, Vol. 40, Issue 9, pp. 1257-1284, Jul. 2000.

[5] Mayr, Josef, et al., "Thermal issues in machine tools," CIRP Annals-Manufacturing Technology, Vol. 61, Issue 2, pp. 771791, 2012.

[6] Y. Li, et al., "A review on spindle thermal error compensation in machine tools." International Journal of Machine Tools and Manufacture, Vol. 95, pp. 20-38, Aug. 2015

[7] Ching-Feng Chang and J. J. Chen, "Thermal growth control techniques for motorized spindles," Mechatronics, Vol.19, Iss 8, pp. 1313-1320, Dec. 2009

[8] Ching Wei Wu, Chia Hui Tang, Ching Feng Chang, Ying Shing Shiao., "Thermal error compensation method for machine center," International Journal of Advanced Manufacturing Technology, Vol. 59, No.5-8, Pages 681-689, Jul. 2012

[9] D. Zhao, B. Yunbo, and Y. L. Ke., "An efficient error prediction and compensation method for coordinated five-axis machine tools under variable temperature," The International Journal of Advanced Manufacturing Technology, Vol. 96, Iss. 9-12, pp. 4431-4443, Jun. 2018.

[10] Richard G. Lyons, Understanding Digital Signal Processing, third edition, 2010.

[11] HEIDENHAIN TNC 640 Technical Manual, Dr. Johannes Heidenhain GmbH, Mar. 2018.

[12] The photo of $5 \mathrm{X}$ machine tool, Buffalo machinery co. ltd., Accessed on Apr. 16 2019. E-link: https://www.axilemachine.com/product.php?id=1. 